\title{
Ischemic Stroke Caused by a Hyaluronic Acid Gel Embolism Treated with Tissue Plasminogen Activator
}

\author{
Sukyoon Lee, MD, Jin-ho Jung, MD, Junghwa Seo, MD, Eung-Gyu Kim, MD, PhD \\ Department of Neurology, Busan Paik Hospital, Inje University College of Medicine, Busan, Korea
}

\section{INTRODUCTION}

Previously, Kim et al. ${ }^{1}$ reported a case in which the patient experienced a complicated cerebral infarction after receiving a hyaluronic acid gel filler injection. We report on the treatment process in this patient, and then discuss the options for managing an acute ischemic stroke (AIS) following a facial filler injection.

\section{CASE}

A 23-year-old man was referred to the emergency department for a sudden ocular pain and vision loss in the right eye that occurred 39 minutes after a perinasal filler injection using hyaluronic acid gel. He denied any medical illness.

His initial blood pressure was $140 / 90 \mathrm{mmHg}$, his pulse rate was 74 beats per minute, and his body temperature was $36.5^{\circ} \mathrm{C}$. An ophthalmologic examination revealed a lack of a pupillary reflex, a dilated pupil, and complete ophthalmoplegia in the right eye. A fundoscopic examination showed the typical appearance of a central retinal artery occlusion with a cherry red spot on the macula, a markedly pale optic disc, and no pulsation of the retinal arterioles. The National Institutes of Health Stroke Scale score was 12, and it included drowsy mentality, left central type facial palsy, and a left hemiplegia.

All laboratory parameters were within the normal limits. The initial brain computed tomography (CT) findings were normal. Diffusion weighted images showed a high signal intensity in the right frontal, temporal, and parietal lobes. The right ophthalmic artery was not seen at the time-of-flight magnetic resonance angiography. There were no steno-occlusive lesions of the intracranial artery.

(cc) This is an Open Access article distributed under the terms of the Creative Commons Attribution Non-Commercial License (http://creativecommons.org/licenses/by$\mathrm{nc} / 4.0$ ) which permits unrestricted non-commercial use, distribution, and reproduction in any medium, provided the original work is properly cited. 


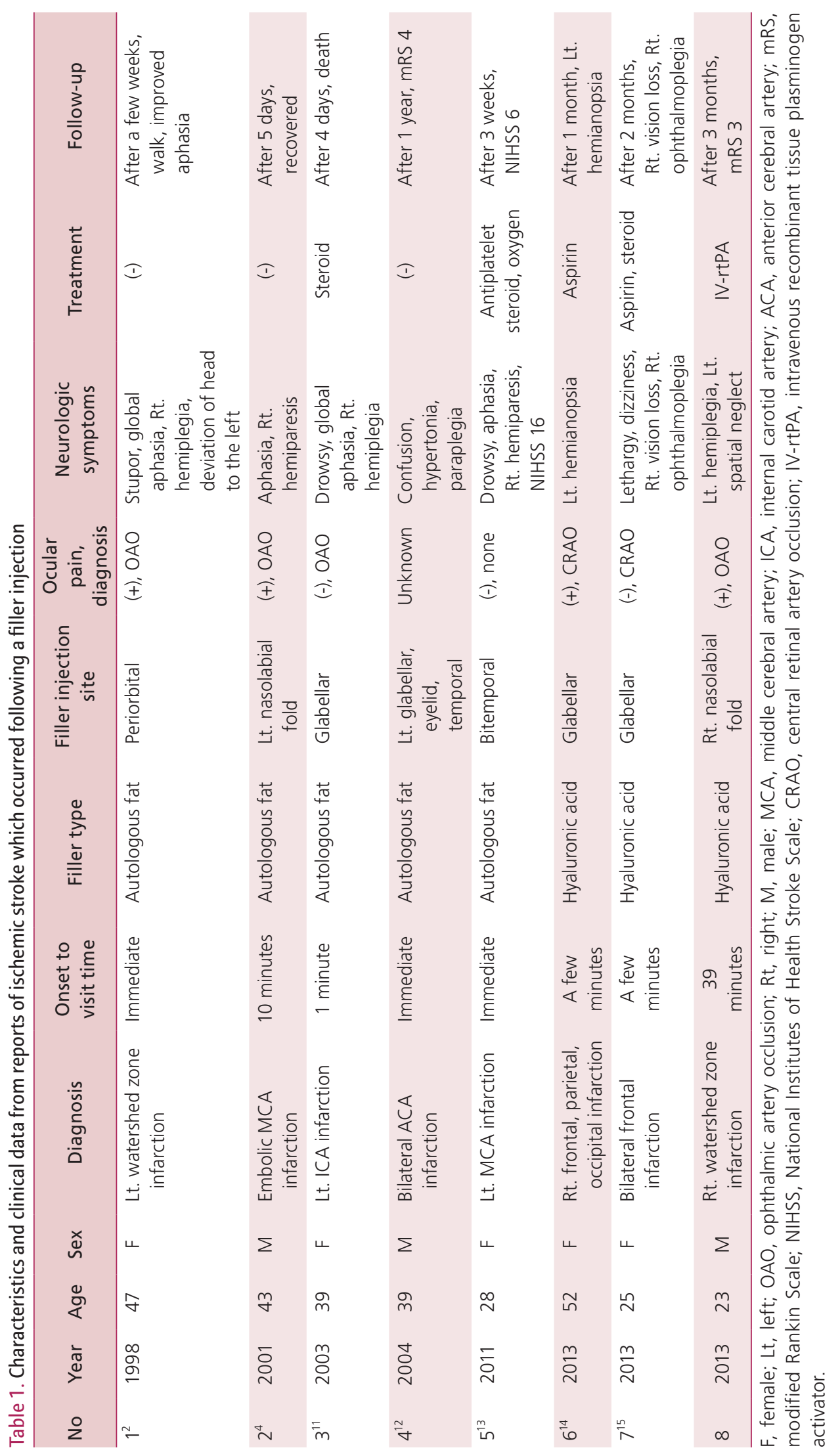


An intravenous recombinant tissue plasminogen activator (IV-rtPA) was administered 75 minutes following the stroke onset. Immediately after the IV-rtPA infusion, the neurologic symptoms remained unchanged with the exception of the patient's complaint of a headache. A followup brain CT scan did not show any hemorrhagic lesions; however, a follow-up CT scan taken on day 2 showed hemorrhagic transformations in the previous infarcted area, as well as a mild midline shift without any evidence of neurological deterioration. The follow-up CT scan was reperformed 27 hours after the IV-rtPA infusion and more enlarged hemorrhagic transformations and midline shifting were observed; in addition, a decompressive craniectomy was conducted.

Although the patient had undergone a decompressive craniectomy, he could walk and he had a modified Rankin Scale score of 3 after 3 months.

\section{DISCUSSION}

Ischemic complications from facial injections of either autologous fat or several other materials have been reported. ${ }^{2,3}$ The injected filler may pass through the ophthalmic and internal carotid arteries, and finally, lodge in the distal middle cerebral artery. ${ }^{3,4}$ Previous studies have demonstrated that blindness and a stroke can occur as a result of the injection of soft tissue fillers in any part of the face. ${ }^{3}$

Complicated AIS cases that have developed after a filler injection are summarized in Table 1. All the cases had occlusion of the retinal or ophthalmic artery and neurologic symptoms that occurred within 2 hours after the filler injection, but there have been no previous case reports regarding the use of an IV-rtPA.

An IV-rtPA is the only proven medical treatment to reduce the effects of AIS, if it is administered within a 4.5hour time window. ${ }^{5}$ There are no known standard treatments for an AIS caused by filler injections. An IV-rtPA significantly improved the microvessel perfusion in the ischemic area in rats. ${ }^{6}$ An IV-rtPA can also be beneficial to ischemic stroke patients with small vessel disease, ${ }^{7}$ and it can be used regardless of major vascular occlusion. On the other hand, thrombus formation can occur around areas with disturbed or slowed blood flow because of the presence of the filler in the artery. Animal studies have been conducted which suggest the benefits of thrombolytic agents in hyaluronic acid embolism. ${ }^{8,9}$ These studies have demonstrated that hyaluronic acid embolism induced the formation of a red thrombus, which is the target of an IVrtPA. Based on this hypothesis, an IV-rtPA may be an alternative treatment option. Hyaluronidase infusion may be a treatment option for a hyaluronic acid gel embolism; ;-10 however, there are currently no case reports or studies demonstrating the use of hyaluronidase for AIS following a hyaluronic acid gel injection.

In conclusion, an IV-rtPA may be used in highly selected AIS cases after a filler injection.

\section{REFERENCES}

1. Kim EG, Eom TK, Kang SJ. Severe visual loss and cerebral infarction after injection of hyaluronic acid gel. / Craniofac Surg 2014;25:684-6.

2. Feinendegen DL, Baumgartner RW, Vuadens P, Schroth G, Mattle HP, Regli F, et al. Autologous fat injection for soft tissue augmentation in the face: a safe procedure? Aesthetic Plast Surg 1998;22:163-7.

3. Coleman SR. Avoidance of arterial occlusion from injection of soft tissue fillers. Aesthet Surg / 2002;22:555-7.

4. Danesh-Meyer HV, Savino PJ, Sergott RC. Case reports and small case series: ocular and cerebral ischemia following facial injection of autologous fat. Arch Ophthalmol 2001;119:777-8.

5. Hacke W, Kaste M, Bluhmki E, Brozman M, Dávalos A, Guidetti D, et al. Thrombolysis with alteplase 3 to 4.5 hours after acute ischemic stroke. N Eng/ / Med 2008;359:1317-29.

6. Fan X, Qiu J, Yu Z, Dai H, Singhal AB, Lo EH, et al. A rat model of studying tissue-type plasminogen activator thrombolysis in ischemic stroke with diabetes. Stroke 2012;43:567-70.

7. Pantoni L, Fierini F, Poggesi A. Thrombolysis in acute stroke patients with cerebral small vessel disease. Cerebrovasc Dis 2014;37:5-13.

8. Chiang C, Zhou S, Liu K. Intravenous hyaluronidase with urokinase as treatment for arterial hyaluronic acid embolism. 
Plast Reconstr Surg 2016;137:114-21.

9. Chiang C, Zhou S, Chen C, Ho DS, Zhang H, Liu K. Intravenous hyaluronidase with urokinase as treatment for rabbit retinal artery hyaluronic acid embolism. Plast Reconstr Surg 2016;138:1221-9.

10. DeLorenzi C. Transarterial degradation of hyaluronic acid filler by hyaluronidase. Dermato/ Surg 2014;40:832-41.

11. Yoon SS, Chang DI, Chung KC. Acute fatal stroke immediately following autologous fat injection into the face. Neurology 2003;61:1151-2.

12. Thaunat $O$, Thaler F, Loirat $P$, Decroix JP, Boulin A. Cerebral fat embolism induced by facial fat injection. Plast Reconstr Surg 2004;113:2235-6.

13. Hu J, Chen W, Wu Y, Chen K, Luo C, Liang Y, et al. Middle cerebral artery occlusion following autologous bitemporal fat injection. Neurol India 2011;59:474-5.

14. He MS, Sheu MM, Huang ZL, Tsai CH, Tsai RK. Sudden bilateral vision loss and brain infarction following cosmetic hyaluronic acid injection. JAMA Ophthalmol 2013;131:1234-5.

15. Paik DW, Jang IB, Kim JS, Lee JH, Choi J. A case of visual loss and ophthalmoplegia following injection of hyaluronic acid into the glabella. J Korean Ophthalmol Soc 2013;54:971-6. 